\title{
3
}

\section{The Introduction of the Prevent Duty into Schools and Colleges: Stories of Continuity and Change}

\section{Joel Busher, Tufyal Choudhury, and Paul Thomas}

\begin{abstract}
Drawing on mixed methods research carried out with school and college staff during 2015 and 2016, this chapter provides insight into how the Prevent Duty 'landed' in schools and colleges during the first 18 months after its introduction in July 2015. The discussion centres on
\end{abstract}

This research was carried out with support from the Aziz Foundation. We acknowledge the contribution of Gareth Harris to the structuring and analysis of the survey data, and the transcription work undertaken by Will Jessop, Tam Sanger and Victoria Butkova.

J. Busher $(\bowtie)$

Centre for Trust, Peace and Social Relations, Coventry University, Coventry, UK

e-mail: joel.busher@coventry.ac.uk

T. Choudhury

Durham Law School, Durham University, Durham, UK

e-mail: t.a.choudhury@durham.ac.uk

P. Thomas

Huddersfield Centre for Research in Education and Society (HudCRES), University of Huddersfield, Huddersfield, UK

e-mail: d.p.thomas@hud.ac.uk 
four key questions: (1) To what extent did staff express overall opposition to or support for the Prevent Duty? (2) To what extent was the Prevent Duty interpreted by staff in schools and colleges as a straightforward extension of existing safeguarding responsibilities? (3) To what extent did staff perceive the Duty to be exacerbating the stigmatisation of Muslim students? (4) To what extent did staff perceive the Duty to have a 'chilling effect' on classrooms and on student voices?

Keywords Prevent $\bullet$ PVE $\bullet$ Education $\bullet$ Policy enactment $\bullet$ Safeguarding $\bullet$ Fundamental British values

In this chapter we examine how staff in schools and further education colleges in England understood, enacted and perceived the impacts of the Prevent Duty during the first 18 months after its introduction in July 2015. In doing so, this chapter provides insight into how the Duty 'landed' during this initial period and begins to empirically draw out themes that are explored further in the subsequent chapters.

We organise our discussion around four questions that cut to the heart of the policy debates that have surrounded the Prevent Duty and the wider Prevent strategy (Chap. 2):

1. To what extent did staff express overall opposition to or support for the Prevent Duty?

2. To what extent was the Prevent Duty interpreted by staff in schools and colleges as a straightforward extension of existing safeguarding responsibilities?

3. To what extent did staff perceive the Duty to be exacerbating the stigmatisation of Muslim students?

4. To what extent did staff perceive the Duty to have a 'chilling effect' on classrooms and on student voices?

This chapter draws on mixed methods research carried out during 2015 and 2016. This comprised 70 semi-structured interviews across 14 schools and colleges in London and West Yorkshire; semi-structured interviews with Prevent practitioners in 8 local authority areas; a national 
online survey of school and college staff in England $(n=225)$ and a series of focus group discussions with policy stakeholders, including individuals from national teaching unions, relevant local and national government departments, and prominent national Muslim and black and minority ethnic (BME) civil society organisations (for further details see Busher, Choudhury, Thomas, \& Harris, 2017).

\section{To What Extent Did Staff Express Overall Opposition to or Support for the Prevent Duty?}

Since the Prevent Duty was first discussed in Parliament, it had been the focus of extensive and often highly critical debate (Chap. 2). We expected therefore to encounter widespread opposition to the Duty among school and college staff, particularly in the context of confidential research interviews and an anonymous survey. Yet while we found some unease about the Duty, and some concerns, we did not find the breadth or depth of opposition that we anticipated.

Within the survey data we found more agreement than disagreement with the statement 'the Prevent Duty on schools and colleges is a proportionate response to a clearly identified problem'. About $54.5 \%$ of the survey respondents agreed or agreed strongly (1-4 on a scale of 1-10), compared with $29.3 \%$ of respondents who disagreed or disagreed strongly (7-10) and $16.2 \%$ who gave a broadly neutral response (5-6).

This picture was supported by the interview data. Here we encountered a number of criticisms and concerns about the Duty. The most frequent of these was about the possible stigmatisation of Muslim students, to which we return below. Alongside this we encountered some scepticism about the effectiveness of the Duty, with several respondents expressing doubts about whether it was possible to effectively identify, or train people to identify, signs that a student was being drawn into terrorism. Such doubts were often reinforced by expectations, and anxieties, that students who were a 'genuine' risk would be adept at not giving themselves away-a clear recognition of student agency and one that 
raises important questions about the use and limitations of the concept of 'vulnerability' in this area of policy and practice (see O'Donnell, 2016).

I think the problem with a lot of this training is that it is very difficult to identify someone who is at risk of this. If people had a very tell-tale sign then you would be able to stop it happening, wouldn't you, all of the time? So how do you successfully spot the correct signs? All you can really do is hope that someone will be able to pick up something that is not quite right and report it to the correct channel. (R32, teacher, secondary school, Yorkshire)

Some respondents indicated they believed the Duty might even be counterproductive because, by making the students more guarded, it could make detection of 'at risk' students more difficult.

I have not had any serious suspicions that any of them might want to go [to Syria] or if they do harbour those extremist views they are very cautious in keeping it to themselves. The kids know exactly what they can and can't say so they are very guarded. So, if anything, it has really driven it underground. (R50, Designated Safeguarding Lead (DSL), secondary school, London)

Yet with the exception of one college, where multiple respondents expressed both concern that Prevent is an anti-Muslim agenda and reluctance to raise this with senior colleagues, few respondents expressed general opposition to the Duty or reported encountering substantial opposition among their colleagues. Furthermore, where opposition was observed, it was described as having dissipated fairly quickly after staff received training, and once the policies and practices that came to be associated with Prevent had been embedded within wider organisational policies and practices (see also Chap. 7).

As we have argued elsewhere, part of the explanation for the relative absence of expressed opposition likely lies in 'pragmatic acceptance' (Busher, Choudhury, \& Thomas, 2019). The Duty was a legal requirement and non-compliance risked significant institutional and professional sanction. As one respondent recalled, in their institution senior management had responded to initial expressions of staff reticence about the Duty by telling them, 
This is a duty and we have to implement it, and if we don't implement it the college could be closed down. So there's your facts, okay? (R1, DSL, college, Yorkshire)

Yet pragmatic acceptance only appears to be part of the explanation, and certainly insufficient to explain observed instances of positive acceptance (see below). Another part of the explanation appears to relate to the fairly widespread perception that, despite some of the concerns described above, the Duty was responding to a real and important issue. For example, the same respondent who expressed concern that the Duty had 'really driven it underground' nonetheless described the Duty as 'completely necessary':

I understood that it was completely necessary. Initially when you don't see [the students] on a daily basis, you think, 'is it; does it really need to be that strong?' But I actually think it probably does; I do see the point of it. Again I do remember just thinking, 'Oh this is just another thing that we need to be vigilant about', but actually it is really important. (R50, DSL, secondary school, London)

Such perceptions were particularly acute in 2015-16, amidst frequent news stories about young people travelling to join the so-called Islamic State. There were also growing concerns about the extreme right at the time, fuelled at least partly by the murder of Jo Cox MP on 16 June 2016, and by emerging evidence that the UK's referendum on leaving the European Union had been accompanied by a significant rise in hate crime (Cavalli, 2019).

What also seems to be relevant to this picture of fairly broad acceptance of the Duty is the fact that the challenges that respondents associated with the Duty were usually described as challenges that could largely be addressed through careful management and suitable training and support. With the exception of the college mentioned above, most respondents drew important distinctions between the potential impacts of the Duty in the education sector in general, and the practice and experience of Prevent within their specific institution, with discussion of the latter largely characterised by stories of effective management and adaptation. 
Indeed, some respondents described the Duty as having positive enabling effects in their particular institution. Some stated, for example, that it had given them more confidence to work with students on topics previously considered too contentious. As one respondent put it,

It's a real sort of backbone to have that behind you, to say 'actually we are entitled to teach this', and especially to tackle the staff and say 'we don't need to pussy foot around this anymore'. (R24, teacher, secondary school, Yorkshire)

Other respondents reported that the Duty had provided an opportunity to reinvigorate work around anti-racism and positive citizenship, which was perceived to have been de-prioritised in recent years within national policy frameworks (Thomas, 2016).

Where we did encounter clear and frequent opposition to the Duty was around the requirement to promote 'fundamental British values' (see also Revell \& Bryan, 2018). Respondents consistently expressed support for, and described extensive experience of, values-based teaching. However, the emphasis placed on the supposed Britishness of these values was repeatedly identified as unnecessary and potentially problematic. Specifically, respondents expressed concern that this framing of values played into societal narratives of exclusion, superiority, fixed cultural boundaries and a them-and-us politics that could too easily play into the hands of the far right and others who prosper from sowing division.

The title 'British values', the title 'fundamental British values', whoever thought that up should've been shot in my opinion. I think it's disgraceful, because it just has too many connotations, it's like tit for tat, 'well you want to be fundamental, well we'll be fundamental'. (R20, DSL, college, Yorkshire)

As a result, respondents in some institutions described subtle forms of individual and institution-level resistance, such as opting to talk about 'school values' or simply 'our values' rather than actively labelling them 'British values' (see also Chaps. 5 and 8). 


\section{To What Extent Was the Prevent Duty Perceived by Staff in Schools and Colleges as a Straightforward Extension of Existing Safeguarding Requirements?}

The idea that the Prevent Duty comprised a straightforward extension of existing requirements to safeguard young people from harms such as child sexual exploitation, gangs, neglect or drug use was central to the government's framing of the Duty and reflected the way that, since 2011, Prevent itself had increasingly been framed in terms of protecting 'vulnerable' people. Such framing of Prevent has faced criticism, however. As discussed in Chap. 2, social workers and social work academics, for example, have criticised this elision of Prevent and safeguarding, arguing that it risks silencing and pathologising individuals rather than understanding and engaging with their practices as acts of dissent, and that the expansion of surveillance entailed by Prevent could actually undermine safeguarding work by generating a climate of suspicion between service providers and the individuals and families with which they work.

To what extent then did our respondents accept or challenge the government's framing of Prevent as a straightforward extension of safeguarding? On one level, our findings were clear: a very significant majority of interview and survey respondents did indeed describe Prevent simply as an extension of safeguarding. Among survey respondents, $86 \%$ agreed or agreed strongly that 'The Prevent Duty in schools/colleges is a continuation of existing safeguarding responsibilities', with only $9 \%$ disagreeing or disagreeing strongly.

The majority of interview respondents also expressed little doubt that Prevent fitted within existing safeguarding practices-as 'just a bit of extra vigilance that were put on us: not an extra duty' (R19, estates manager, college, Yorkshire). The Duty was frequently described as entailing little more than subtle adjustments, or even just some relabelling of what they were already doing. 
I've always seen Prevent as being a model of safeguarding. I don't see it as much different from safeguarding. Indeed, we've had a line in our safeguarding for extremism for many, many years, so it's been a part of our safeguarding. (R20, DSL, college, Yorkshire)

A number of factors have contributed to this broad professional acceptance of the Prevent-as-safeguarding policy frame. First, the organisational processes used to meet Prevent-related obligations were in practice very similar to those used for safeguarding, with Prevent-related training, monitoring, referrals and coordination all managed through existing, albeit in some cases expanded, safeguarding structures and processes. Here, an important part of the backstory is the extent to which educational institutions in the UK had, particularly since 2001, already become sites of extensive surveillance, usually in the name of student safety (Taylor, 2013). By the summer of 2015, online safety was already high on the agenda, the use of software to block access to 'dangerous material' was widespread, and there was growing use of digital systems to report and collate safeguarding concerns, meaning that on a day-to-day level Prevent felt to most respondents to be largely a case of adapting and repurposing existing tools and procedures.

Second, there was considerable similarity between what the respondents' understood as the signs and indicators that a young person is being drawn into terrorism and the behaviours they had previously been trained to identify as indicators of 'vulnerability' to other safeguarding issuessuch as sudden changes in behaviour, disposition and friendship groups.

When you look at the action it's exactly the same as the actions we'd take against FGM [female genital mutilation] and against child sexual exploitation ... It is a safeguarding issue. It's the same, it's about keeping children safe from predators. If you look at, well when I look at a profile of a radicaliser, you know, and a groomer, it's the same tactics and they're targeting the same sorts of vulnerabilities in children. (R61, DSL, secondary school, London)

Third, these narratives of policy and practice continuity were consolidated as staff incorporated the new requirements into their existing 
practice and organisational culture through activities such as 'mapping' or 'self-assessment' exercises. Without exception, these exercises, in which staff essentially assessed what they needed to do to ensure compliance with the Duty, were reported to have revealed to participants that they were already largely addressing the requirements of the Duty-a 'realisation' often accompanied by strongly recalled feelings of relief. Such processes reflect established patterns of response in schools as they comply with new policy (Ball, Maguire, \& Braun, 2012), and helped to generate narratives of policy and practice continuity both for the 'safeguarding' dimension of the Duty and for the curriculum requirements around the promotion of fundamental British values.

We went through [the policy documentation] and decided whether we were meeting what was required as a school or whether we still had some work to do in some areas. For a lot of them we decided that we were already providing adequate provision through our policies ... We had a copy of the document each, [name A] was leading the meeting and we read through all of the individual points and we discussed the elements that we cover. So sometimes [name B] would be saying, well we already covered this throughout PSHE, or I would be saying, actually in our scheme of work within history we promote tolerance and democracy through this. (R32, teacher, secondary school, Yorkshire)

These narratives of continuity played an important role in smoothing the introduction of the Duty and softening possible opposition. This was partly about the relief that staff experienced as the Prevent Duty came to be seen as something that did not entail substantial changes to their dayto-day practices. They also helped to 'cushion' fears about possible negative consequences and implications of the Duty.

One of the things that we've found when we've been rolling out the training is staff can get quite nervous about it. They feel, some of them, not all, feel that, what does it exactly mean 'referring our students'? Are we going to lose the element of trust? But we talk about duty of care, which our lecturers have always had for years. Whether or not that's making sure the students are happy, safe, on the right course, all those kinds of elements. 
And this is just another thing. But we kind of like cushion it with, we refer to our safeguarding team, which I think does make some people feel better. (R2, middle manager, college, Yorkshire)

The fact that it sits under the safeguarding thing makes things much easier with staff, and it's less sort of racist in its tones, and the assumptions and the sort of Islamophobia kind of viewpoint on things disappears when you're saying 'we're just trying to keep kids free from grooming, all types of grooming'. (R21, middle manager, secondary school, Yorkshire)

Yet these narratives of continuity were not entirely straightforward, and there were several instances in which they were disrupted, at least temporarily. In the following quotes, for example, while Prevent is seen as being similar to safeguarding, the straightforward narrative of continuity is disrupted either by the additional 'depth' of surveillance that Prevent entails or by the way that Prevent is seen to have refocused work on safeguarding.

[It is] like safeguarding: we must be there to protect and to be there for the young and vulnerable people, the vulnerable adults and so on. But then Prevent is a little bit more deeper, where we have to know what is terrorism, what is radicalisation, what to listen for. (R19, estates manager, college, Yorkshire)

Obviously, safeguarding had fallen off the radar really for Ofsted, and then suddenly it zoomed. [...] we thought [...] Ofsted were relaxing about it a bit, suddenly it's right up there, and now they're fierce about it. (R1, DSL, college, Yorkshire)

Other respondents observe how, in comparison with previous safeguarding expectations, the Prevent Duty had foregrounded and intensified security and reputational risks, and induced or deepened anxieties about 'missing something'.

I think what the Prevent agenda does, is, as a teacher it makes you feel anxious and that you will miss something in some way, that you will get into trouble because you'll miss something. (R5, senior leader, secondary school, Yorkshire) 
There were also other comments and observations that suggest the continuity between safeguarding and Prevent was more unstable than it might at first glance appear. When asked, teachers were often uncertain about what happens to referrals once they go outside the school or college, and some respondents questioned whether Prevent-related referrals might in fact result in students coming under wider state surveillance mechanisms. For example, one respondent mused over what it meant once a student was on 'the Prevent list':

[Is that] being tracked, followed, all his movements for, I don't know, is that forever? ... You are on a database. You are on there aren't you? That's it forever more? If anybody wanted to look it up you are there? All your details and where you live and who you associate with? (R48, middle manager, secondary school, London)

In another interview, an institutional safeguarding lead observed that in other areas of safeguarding they are able to obtain a clearly evidenced assessment of their local risk profile, but that this has not been the case with Prevent-related concerns.

With Prevent, I mean, there's no data available, there's no, it's all secret secret. We're a category two, or category one borough, so it's a high risk borough, but low referrals under eighteens, very low. I don't know what the over eighteen referral rate is, do you know? And there's no comparative data so you can't compare it to other boroughs: it's very, it's all quite clandestine so I can't tell you if things are better elsewhere. [...] What is the actual risk? Like, we know, for example with female genital mutilation we know how many, up to about three years ago, two years ago, were affected in [name of borough]. So like, wow, you know, it's huge, so we've got to sort this out, you know? But we don't know how many are affected [in terms of Prevent-related concerns], I don't know how many are affected, and all I know is that we're category one, or whatever, but there's no, I can't find a ..., there's ..., no-one's given us a description of what that is. Well why is it a category one? What is it? I think it's just based on the number of Muslims, but I don't know. Is it? (R61, DSL, secondary school, London) 
Wider evidence also problematises narratives of straightforward continuity. Within our survey data, we found that a substantial proportion of respondents-33\% across the whole sample, but 54\% among senior leaders-describe the introduction of the Prevent Duty as increasing their personal workload 'a lot' or 'a moderate amount', at least initially. And after the first year of the Duty being in place, there had been a dramatic 75\% year-on-year increase in referrals to Channel, the government's anti-radicalisation mentoring scheme (Chap. 1).

As such, while the Prevent-as-safeguarding frame appears to have achieved fairly broad professional support, this narrative of continuity was not quite as straightforward as it might at first have seemed. It contained within it anxieties about the heightened risks and pressures that Prevent brought with it, and there were moments during the research interviews in which the narrative of continuity was disrupted, at least temporarily, as respondents struggled to reconcile apparent contradictions. Furthermore, the dominant narrative of continuity, and the significant professional relief that accompanied it, was at least partly a product of the policy enactment processes through which staff had actively sought to ensure that the Duty fitted within existing practices, policies and their own personal comfort zones.

\section{To What Extent Did Staff Perceive the Prevent Duty to Be Exacerbating the Stigmatisation of Muslim Students?}

Where our respondents' perceptions of the Prevent Duty coincided most closely with criticisms of the Duty and of Prevent more broadly was in relation to concerns that the Duty could exacerbate the stigmatisation of Muslim students. There was strong support both within the survey and interview data for the idea that the Prevent Duty was about all forms of extremism and not just that associated with $\mathrm{Al}$ Qaeda or Islamic State. Among survey respondents, $82 \%$ agreed or agreed strongly, and just $13 \%$ disagreed or disagreed strongly, with the statement 'the Prevent Duty is about all forms of extremism'. Nonetheless, over half (57\%) the survey 
respondents said that the Duty has made Muslim students more likely or considerably more likely to feel stigmatised. This pattern was stronger still among BME respondents, where $76 \%$ said that the Duty made Muslim students more likely, or considerably more likely, to feel stigmatised.

These findings were supported by the interview data. Here we again found broad agreement that the Duty was intended to address all forms of extremism. Respondents across all of the schools and colleges also spoke about how they and, in most cases, their colleagues had sought to ensure the Duty did not result in Muslim students feeling alienated or stigmatised. Respondents reported that staff training had emphasised that the Duty was about all forms of extremism, that within their institution Prevent had been closely linked to ongoing work around anti-racism and anti-discrimination, and some described working with older Muslim students in their institution to assess how teaching materials relating to Prevent might be perceived and interpreted by other Muslim students.

Nonetheless, concerns persisted that Muslim students might be experiencing greater stigmatisation as a result of the Prevent Duty. These concerns were sometimes externalised and projected onto other institutions. In several cases interviewees drew distinctions between institutions, like their own, where staff were seen to be well trained, supported and managed, and those where 'knee-jerk reactions' and staff 'jumping to conclusions' were more likely to give rise to poor decision making or the Duty being 'done badly' (Busher et al., 2019, p. 456). Yet some respondents also expressed concern about how the Duty might be affecting students within their own institution.

Some of these concerns were related to respondents' appreciation of the wider societal context of social and political marginalisation facing Muslim students and colleagues, including an awareness of the history of and debates surrounding Prevent and the Prevent Duty.

I think some of the negativity that I've picked up on, and it's not been said in the training sessions, it's just in conversations, that although the presentation is all around extremism, radicalisation - that it also includes radicalisation and extreme of right-wing as well as ISIS, and animal rights and the Northern Ireland issues - I think still people still believe it's actually aimed 
at Muslims and ISIS ... They believe that Prevent has come about because of Muslims. I don't think they think Prevent has come about because of animal rights or right-wing. (R17, student advisor, college, Yorkshire)

Respondents' concerns were also bound up with reflections on their own practice and the challenges of dealing with issues around unconscious bias and the limits of their own knowledge and understanding. Some respondents observed that, regardless of the intention of staff, Muslim and non-Muslim students might be treated differently, simply because the mainly white and non-Muslim staff were likely to feel more familiar, and therefore more confident making judgement calls about what did or did not constitute a 'genuine' concern, when dealing with white students and possible issues of far right engagement:

[The anxiety of staff] is not about right-wing extremism, which I think they are confident in challenging. I think it's anything to do with Islam, anything to do with the Muslim side of things, anything to do with Syria. They're worried that they'll say the wrong thing, do the wrong thing, be seen as saying and doing the wrong thing. (R1, DSL, college, Yorkshire)

Discussion of these concerns was clearly challenging for respondents, particularly when this tipped into reflections that they might themselves be contributing to forms of racialised stigmatisation. One respondent, for example, reflected on how, when a Muslim primary school student had said that their father was not contactable at the time, this, along with a perception that that particular student's 'life seems to be ruled by the mosque', led them to wonder whether the father might have travelled to Syria — something that with hindsight seemed like a 'massive leap' (R28, teaching assistant, primary school, Yorkshire).

This left some respondents struggling to navigate acute and shifting tensions and anxieties as they tried to pick their way through a complex and seemingly sometimes competing set of responsibilities and emotions. In the following passage, for example, a respondent describes picking up on changes in the behaviour of a student that they think could possibly 
indicate a process of radicalisation; how reflection on the nature of these indicators raises fears and a sense of guilt when they perceive that they might be acting in a way that is racist; but also how these fears are intertwined with worrying that failure to escalate the case further could result in 'missing something'; and how they eventually come to rationalise this dilemma.

she came in with some Pakistani friends. She'd met her father for the first time in years, and she was wearing a headscarf. And of course, it's hard, as somebody who'd known her for 3 years, with absolutely no link to her Pakistani heritage, the first thing I was thinking was 'What's she wearing that scarf for?' She's with this group of her boyfriend and some Asian girls, and she's now wearing a headscarf. Now that's what I mean - you can't become complacent. I admit to feeling a sense of panic, when I saw that, you know, knowing that she was a vulnerable, looked after child, my first reaction was, 'Oh my god, she's been radicalised somehow. She's got this boyfriend, she's within this group, what on earth has happened?' And of course when you unpick the situation, it wasn't like that at all, I think she was just crying out for a group where she fitted in ... what you feel is, you know, you're honestly looking at the situation thinking, you've got a girl who has a half-Pakistani heritage, and yet you're deeming her at risk of radicalisation because she's exploring that part of her culture. That feels, you almost feel racist for thinking that, do you see what I mean? Thinking that you'll get it wrong, and yet, your overriding concern is that you'll miss something. [...] I suppose that's what I'm trying to get at, and I don't mean to blame it [the Prevent Duty], because there's an overriding system, I think, you know, better to be vigilant and make that mistake, and find out, like we did, that there was absolutely nothing to be concerned about. [...] Does that make sense? (R5, senior leader, secondary school, Yorkshire)

As such, while few respondents perceived in the Prevent Duty an intention to stigmatise Muslim students, there were nonetheless persistent concerns that this could be one of the outcomes. This raised difficult questions for staff and their institutions about how to mitigate these risks and how to resolve and manage the attendant anxieties. 


\section{To What Extent Did Staff Perceive the Duty to Have a 'Chilling Effect' on Classrooms and Student Voices?}

The final question concerns whether staff perceived that the Prevent Duty was, as anticipated by some critics, having a 'chilling effect' on classrooms and student voices. Here, as expected, respondents again raised a number of concerns. Several reflected on the possible tension between wanting to create open spaces for discussion and the effect that reporting requirements might have on students.

I think particularly at the age we're dealing with, it's more them saying things that don't quite sit right [...]. But it is hard, because I can totally see why some of the criticism has come about. If children feel that they can't talk about things or disclose things, then you're not creating the environment that you want. (R28, teaching assistant, primary school, Yorkshire)

Some respondents also spoke about self-censoring among students. For example:

They know they can't say things, they know that they are not allowed to get involved in things, they know it will bring them trouble if they make comments or say things. (R55, senior leader, secondary school, London)

I'd think they'd be quite vocal, but I think they're afraid to be vocal [...] I just think like with everything that's going on they don't want to be singled out in terms of - or being misinterpreted. There has to be a culture where they can speak freely and discuss things but I don't think that there is such a culture. (R64, support worker, secondary school, London)

Yet respondents also spoke at length about how they and their institutions had sought to address these challenges, often by reinvigorating or initiating new activities intended to foment discussion about topics around politics, peace, conflict and discrimination. These activities included special assemblies, sometimes led by an external expert speaker; 'drop-down days' where the normal curriculum was suspended to allow 
groups of students or the whole student cohort to focus on what were perceived to be relevant issues; the inclusion of anti-extremism material during form time in schools; the inclusion of new material within existing curriculum; and extra-curricular activities, such as debating clubs, and intercultural dialogue events. Respondents often perceived these initiatives both to have been largely successful and to have softened staff concerns about the impacts of the Duty.

I think in the early years when we did it, I think maybe because of the things that were being said around, [students] said 'we can't say that to you because you can report us'. So, for me, I had to convince them that, 'that's not what we're here for. We're here to actually create a safe environment for you to be able to share your views and hear what other people say and that will help to bring a balance to your own perspective of things'. So yeah, so I think it varies, but as we're going on with it I think people are getting to understand part of the reasoning behind the Prevent agenda. (R68, support worker, college, London)

Some respondents even argued that the Duty had actually opened up more opportunities for dialogue and discussion on issues around extremism, politics and conflict. Here, the Duty itself was reported to have been a 'vehicle' for discussion.

I do think it serves a purpose in school because, like I said, it's a vehicle for discussion and it's almost, it's something that's been a bit taboo in the past and it's made it, it's brought it to the forefront of school life, and it's something that now not only should be discussed but it has to be discussed. (R24, teacher, secondary school, Yorkshire)

Others saw in the Duty an opportunity to pick up again on approaches to equality and anti-racism that go beyond simple proscription of 'unacceptable' language to critical reflection on how students are engaging with the world around them.

If students are making racist comments, you know, it's not saying 'we don't want any of that language in here', and job done: its more about 'why do you feel like that?', 'where have you got that information?' [...] I think it's 
a new way of thinking. Actually it's not a new way of thinking: it's the old equality and diversity way of thinking, but I think that's slipped over the past few years and we need a lot of input in bringing that back. (R12, student support officer, college, Yorkshire)

The survey data paint a similar picture. To our initial surprise, only $12 \%$ of respondents stated that the Duty had resulted in less open discussions on topics such as extremism, intolerance and inequality, compared with $32 \%$ who stated that it had made no difference, and $41 \%$ who stated that the Duty had actually led to more open discussions around these topics.

These findings would appear to bring into question some of the assumptions about the likely impact of the Duty. While staff had clearly been aware of and alert to the possible negative effect of the Duty in terms of producing a 'chilling effect', most appeared fairly confident that such risks had largely been mitigated. Yet we are only talking about staff perceptions here: it does not tell us how accurately those perceptions reflect the lived reality of students themselves (see Chaps. 4 and 8), and some critics have argued that reports of increased classroom debates in the wake of the introduction of the Duty might be 'conflating the abstract discussion of a news story with a more authentic, dialogic, exchange of views' (Faure-Walker, 2019, p. 372).

Furthermore, it is noticeable in both the survey and interview data that BME respondents were generally less optimistic than white British respondents about the ability of staff to mitigate the possible negative effects of the Duty in this regard. In the survey data, for example, $29 \%$ of BME respondents state that the Duty has led to less open discussions, $34 \%$ that there has been no change and only $25 \%$ that there have been more open discussions. This is in sharp contrast with their white British colleagues, among whom just $9 \%$ reported a decline in open discussions, $32 \%$ stated that there has been no change and $43 \%$ stated that the Duty has led to more open discussions. Given evidence elsewhere about selfcensorship among people who perceive themselves to be a focus of security policy attention (Mythen, Walklate, \& Khan, 2013; Younis \& Jadhav, 2019), this variation warrants serious attention. 


\section{Conclusions}

By exploring the enactment of the Prevent Duty during the first 18 months after its introduction, the findings and discussion presented in this chapter begin to highlight the complexity of how the Duty has played out 'on the ground'. In doing so, they challenge the more straightforward narratives often offered by advocates and critics of the Duty.

While supporters of the Duty might point to our findings as evidence of the easy fit between safeguarding and Prevent, and as evidence that the Duty is not having the type of chilling effect that some anticipated, it is clear that the Prevent-as-safeguarding policy frame was not quite as stable as it might at first glance appear. It is also clear that both the seemingly broad professional acceptance of the Duty and the limited reports of a chilling effect in classrooms were to an important extent a product not of policy design as such but of processes of policy enactment by professionals as they sought to minimise the Duty's disruption of their existing practice and institutional culture and ethos.

Similarly, while some of the findings resonate with criticisms of the Duty, particularly around concerns that it has the potential to exacerbate the stigmatisation of Muslim students, they also draw attention to how education professionals have worked to mitigate those risks and have identified opportunities to reinvigorate areas of work around citizenship, democracy, equalities and anti-racism that had previously been de-prioritised.

Such observations do not lend themselves easily to grand narratives of policy success or failure. They might however take us a little closer to an appreciation of something approaching the reality of what the Prevent Duty looks like in practice. 


\section{References}

Ball, S. J., Maguire, M., \& Braun, A. (2012). How schools do policy: Policy enactments in secondary schools. Abingdon, UK: Routledge.

Busher, J., Choudhury, T., \& Thomas, P. (2019). The enactment of the counterterrorism 'Prevent duty' in British schools and colleges: Beyond reluctant accommodation or straightforward policy acceptance. Critical Studies on Terrorism, 12(3), 440-462.

Busher, J., Choudhury, T., Thomas, P., \& Harris, G. (2017). What the Prevent duty means for schools and colleges in England: An analysis of educationalists' experiences. Coventry, UK: Centre for Trust, Peace and Social Relations.

Cavalli, N. (2019). Did hate crime double after Brexit? CSI34. Oxford, UK: Centre for Social Investigation. Retrieved from http://csi.nuff.ox.ac.uk/wpcontent/uploads/2019/06/CSI34_hate-crime.pdf

Faure-Walker, R. (2019). Teachers as informants: Countering extremism and promoting violence. Journal of Beliefs \& Values, 40(3), 368-380.

Mythen, G., Walklate, S., \& Khan, F. (2013). 'Why should we have to prove we're alright?' Counter-terrorism, risk and partial securities. Sociology, 47(2), 382-397.

O'Donnell, A. (2016). Securitisation, counterterrorism and the silencing of dissent: The educational implications of Prevent. British Journal of Educational Studies, 64(1), 53-76.

Revell, L., \& Bryan, H. (2018). Fundamental British values in education: Radicalisation, national identity and Britishness. Bingley, UK: Emerald.

Taylor, E. (2013). Surveillance schools: Security, disciple and control in contemporary education. Basingstoke, UK: Palgrave Macmillan.

Thomas, P. (2016). Youth, terrorism and education: Britain's Prevent programme. International Journal of Life-Long Education, 35(2), 171-187.

Younis, T., \& Jadhav, S. (2019). Keeping our mouths shut: The fear and racialized self-censorship of British healthcare professionals in PREVENT training. Culture, Medicine, and Psychiatry, 43(3), 404-424. 
Open Access This chapter is licensed under the terms of the Creative Commons Attribution 4.0 International License (http://creativecommons.org/licenses/ by/4.0/), which permits use, sharing, adaptation, distribution and reproduction in any medium or format, as long as you give appropriate credit to the original author(s) and the source, provide a link to the Creative Commons licence and indicate if changes were made.

The images or other third party material in this chapter are included in the chapter's Creative Commons licence, unless indicated otherwise in a credit line to the material. If material is not included in the chapter's Creative Commons licence and your intended use is not permitted by statutory regulation or exceeds the permitted use, you will need to obtain permission directly from the copyright holder.

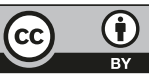

